\title{
Construction Strategies of School-based Individualized Teaching Actions under the Visual Threshold of New Seminar
}

\author{
Lingling Qu \\ School of Economics and Management \\ Leshan Normal University \\ Leshan, China 614000
}

\author{
Min Kuang \\ School of Economics and Management \\ Leshan Normal University \\ Leshan, China 614000
}

\begin{abstract}
The change of the times has also brought about the disorderly dissemination of knowledge. How to enable students to actively and widely accept the pluralistic knowledge has always been a new issue that educators are faced with. Based on this starting point, this paper puts forward the construction strategy for school-based individualized teaching action under the visual threshold of new Seminar, which not only sublimates the former research-and-discussion teaching method, but also treats the "positive", "negative" and even "Buddha-like" students in the "application-oriented" and "research-based" schools differently. At the same time, the action strategy also discussed in combination with practice, which provides an important reference and inspiration for educators who want to achieve the goal of "active learning and vivid teaching".
\end{abstract}

Keywords—new Seminar; school-based; individualized teaching; interaction; experience; action strategy

\section{INTRODUCTION}

With the emergence and development of new things around us, "digital home", "shared bicycle", "Internet +", and "MOOC era" are all changing our lives. At the same time, the way of thinking of the new generation of people is also changed. Students living in such an "E-era" are no longer as comfortable with the repetitive and identical "cramming" education method as before; Because of the diversification of the way of understanding knowledge and approaching the new world, all the educators are facing a common problem: how to carry out the non-one-way teaching method of antiindoctrination so as to truly realize "teaching students according to their aptitude". Based on this, the author combines his previous teaching practice and divergent reflection, creatively puts forward the strategy for schoolbased individualized teaching action under the visual threshold of new Seminar, and adopts different teaching methods for different students, which not only meets the needs of students' individualized learning, but also inputs more innovative forces into the requirements of talents in the new era.

\section{CONCEPT INTERPRETATION AND CONNOTATION}

\section{A. "Seminar" and "New Seminar"}

Seminar is a typical teaching method that breaks the indoctrination teaching and gives full play to students' learning initiative. ${ }^{1}$ The initial origin was in Germany. In early 19th century, in order to implement the concept of the unity of teaching and scientific research, Humboldt University of Berlin was devoted to promoting the integration of teaching and scientific research. In this process, a basic teaching model and system, Seminar, was gradually developed. ${ }^{2}$ The essence of Seminar is that teachers and students carry out discussion on a specific problem to deepen the understanding of a certain topic and achieve the educational goal of "learning to gain, teaching while learning, day-to-day learning" through fully tapping the learning potential of students and carrying out multi-angle and multilevel cognitive interaction. ${ }^{3}$ The connotation of "New Seminar" is to use the teaching idea of research interaction, but it breaks through the way of topic discussion or special debate which is often used in the past education, and uses a new method of teaching guidance which combines vivid teaching with research learning.

\section{B. School-based}

The so-called "school-based", as its name implies, is to give up the "one-size-fits-all" and "all the same" way of education that each school has conducted in the past, and combine its own school positioning, especially the requirement for exporting talents, to foster a diverse range of targeted abilities, knowledge and skills. "Seeking

Fan Wenxiang, Li Yuan, Zhang Yichun. Exploration of Seminar Teaching Model Based on the Concept Flipped classroom [J]. Higher Education of Sciences, 2017 (4): 32.

Xie Xiaoyu, Liu Shiyu. Discussion Teaching: The Practical Application of Seminar Teaching Model in Undergraduate Teaching [J]. Theory and Practice of Education, 2013 (33): 50-52.

Gu Liliang, Chen Fanjun, Zhang Junling et al. Important role of Seminar course in postgraduate training: Taking Seminar of plant nutrition graduate students in China Agricultural University as an example [J]. Academic Degrees \& Graduate Education, 2013 (7): 42-44. 
development by people-oriented and promoting growth by school-based".

\section{Individualized Teaching}

The Encyclopedia of International Education interprets individualized teaching as: the teaching form based on individual rather than group. It allows students more flexibility in learning steps and time than group-based methods such as lecture or group teaching, and that the extent to which teaching is adapted to individual needs varies with the particular method used. ${ }^{5}$ The "Dictionary of Teaching" interprets individualized teaching as: teaching designed to meet the needs, interests and abilities of each student. ${ }^{6}$

To sum up, "individualized teaching" should be a kind of teaching design which is based on students' active participation, supported by the concept of "group-oriented, giving consideration to differences", and based on flexible teaching organization and multiple teaching strategies, so that all students can obtain full and harmonious development. $^{7}$

\section{FEASIBILITY STUDY OF SCHOOL-BASED}

INDIVIDUALIZED TEACHING ACTIONS UNDER THE VISUAL

\section{THRESHOLD OF NEW SEMINAR}

The arrival of the new era calls for the emergence of new teaching methods. The implementation of school-based individualized teaching action under the visual threshold of new Seminar from the following three perspectives has certain feasibility.

\section{A. The White Sand Causeway in Green Shade of Poplar - Different from the Traditional Teaching Mode}

The traditional teaching mode of "teachers teaching and students listening" has a history of thousands of years. We cannot deny the influence of this kind of teaching on the transmission of knowledge. However, with the emergence of more and more channels to acquire knowledge, it seems that "interpreting doubts" and "experiencing" can cater to the current students' tastes more. "New Seminar Teaching Method" is like a fresh air of education, turning "one-way teaching" into "two-way interaction". From passive acceptance to active learning, the understanding of knowledge also grows from being told to leading. The mode of group orientation breaks through the past personal thinking, and sharing experience makes more interdisciplinary knowledge invisible and internalized. All these show its unique personality, respect more for the

\section{$4 \quad$ Chu Renjie. Seeking development though People-oriented and} promoting Curriculum Reform by School-based [J]. Teachers, 2015 (3): 57.

T. Husen ed. Volume 5 of the International Education Section. Guiyang: State Education Press, 1990: 75.

6 Gu Mingyuan ed. Volume 5 of the Dictionary of Education. Shanghai: Shanghai Educational Publishing House, 1990: 35.

Wang Qing. Research on the Action of Individualized Teaching in the Context of Large Classes [D]. Jiangsu: Yangzhou University, 2013: 10 reflection and breakthrough of the children themselves. Compared with the traditional teaching method, it can better achieve the seamless integration of "teaching" and "learning". See "Fig. 1" for a comparison of the two.

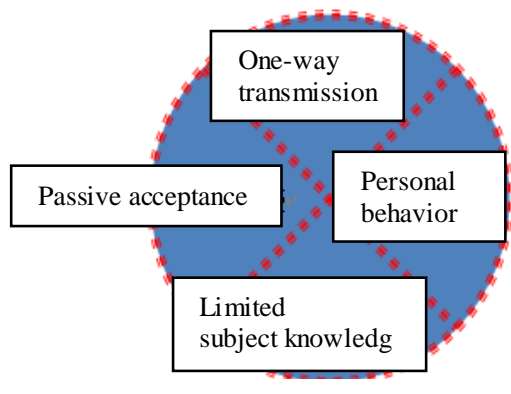

Traditional teaching mode

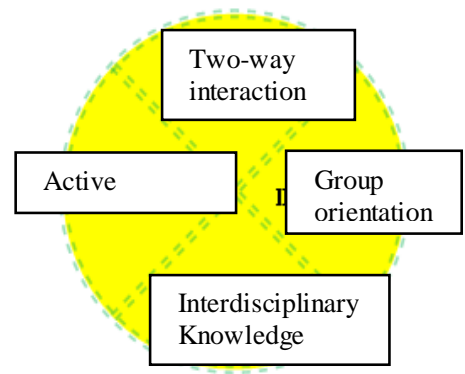

New Seminar teaching mode
Fig. 1. The comparasion of new Seminar teaching method and traditional teaching method.

\section{B. Sunny Mountain Snow Castle - Differentiating the Positioning of Application-oriented and Research-based Schools}

Along with the type classification of talented person made by China, each school also has made the positioning according to their actual situation. For example, many colleges and universities are roughly divided into two categories: application-oriented and research-based. Application-oriented talents pay more attention to cultivation of skills and operation, and research-based type attaches importance to theoretical discussion and logical analysis. Different school positioning decides whether to pay more attention to the deepening of knowledge or to the side sublimation in the process of students' training and whether to master the knowledge of this subject or the content of multi-angles. The establishment of the purport of "schoolbased" organically combines school positioning and teaching methods, so that the cultivation of talents is more targeted, and at the same time has distinct school characteristics, which is exactly the organic positioning of talents we have been pursuing.

\section{Spring Breeze Blows the Railing and Dewdrops Makes the Color of Flower Thicker -Distinguishing the Tolerance Level of Students with Different \\ Characteristics to Knowledge}

"One hundred is all manner of man." ${ }^{8}$ As the main body of each school, the students also have a variety of personality traits, characteristics and features. How to deal with their emotions and understanding and grasp of the knowledge at the same time has always been the medium that every educator is willing to pursue. We can divide the students into three categories: positive type, negative type, and average

\footnotetext{
$8 \quad$ Yao Xueyin. Li zicheng. Volume 1, chapter 6, Lijiang Publishing
} House, 2010 edition. 
type, in the more fashionable word, "Buddha-like Neutral" ${ }^{9}$ students, who are neither radical nor silent. They can do anything. However, they are in an ambiguous state as for understanding knowledge. For these three styles of students, educators also worry a lot. The "individualized teaching" proposed by the author is to divide the students into different groups, so they face the same task together rather than a single individual deal with the knowledge. They make use of the cooperation and influence between each other to get selfstudy and reflection, so as to improve the degree of tolerance to the knowledge.

\section{IMPLEMENTATION OF THE STRATEGY FOR SCHOOL-} BASED INDIVIDUAL TEACHING ACTION UNDER THE VISUAL THRESHOLD OF NEW SEMINAR

No matter from which point of view, the strategy for school-based individual teaching action under the visual threshold of new Seminar has feasibility and practical significance. Taking this as a starting point, the author uses this action strategy in practice, and the results are very good.

\section{A. Practice Process}

The author's school is the national ordinary normal university, of which the orientation is the comprehensive application-oriented university. This kind of background also makes the talent cultivation has characteristic and traits, and the practice ability, the quality will, and even the skill value need to reach a new height. Based on this, the author has pertinently adopted one of them to carry on the reform and the practice.

1) Organizational form: This course is taught to students majoring in accounting in the third year of the university. The general class size is about 45 students. According to the characteristics of the course, the teachers divide the teaching contents of the whole semester into several sections, some of which are completed independently, some of which are done in groups. There are roughly 2-3 persons in one group, and totally 12-13 groups according to the length of the semester. The primary evaluation approach is to focus on discussion and interaction, taking into accounts the skills and individual characteristics of each student, based on the performance of each individual in the team and the extent to which they can understand in the discussion.

2) Strategies for teaching action: The first strategy is that after listening to the teachers' teaching the corresponding knowledge, students don't use the way of writing, but use the way of painting, to connect the knowledge with their own characteristics, which requires the students to think about their own personality after giving full play to their imagination. The purpose of doing this is that teachers can apply their psychological knowledge to

9 Internet buzzwords, which came into fashion in December 2017, was originated in a Japanese magazine in 2014, referring to a way of life and lifestyle that holds negative attitude towards everything. (From Baidu encyclopedia www.wapbaike.baidu.com) roughly carry out the student personality identification through the students' homework and the classroom performance, and group them, so that positive, negative and Buddha-like types are interspersed.

The second teaching action strategy is no longer the stage of one-way transfer of knowledge. After the teacher gives you an overview of the main idea and key points of the whole course, the remaining chapters will be deduced in different ways according to the grouping situation.

The first is to use PPT form to present the content of the chapter. It may seem simple, but it will be difficult to bring new ideas out of the old, and there should be continuity between the members of the group, so as to strengthen the relationship between the members of the group, and other students can understand the new knowledge from different angles in a special way, which is more attractive than the traditional explanation by the teacher alone. In the process of our practice, when we talk about green production, some students quoted the new energy vehicle "Tesla" as the core for in-depth discussion, so that we are deeply impressed; the second is live performance. In the past, some people always said, "life is like drama and drama is like life", which is indeed truth to some extent. We ask students to put the content of course in the script, and perform it in class. Few people try it in non-performing classes, which is a challenge for all students. Especially when it involves to some company links, some students can understand the state of mind as BOSS and the helplessness as a small potato through consulting the materials. This experience can't be compared by other ways. The third is micro movies, which require students not only to write scripts, but also to act, edit and compile the course into a complete micro movie video. This is indeed not a simple matter. However, the future of society's demand for talent and the diversity of students' learning paths now, the availability of optional software and the admission of App, open a door for students although seem difficult. Through this door, students can understand the different world, and use both hands and brains at the same time. From the results of practice in the past, the students who do well in micro-movies have creativity and perseverance. We even have students who specialize in editing, which really helps to cultivate skilled talents.

The teaching action strategy three is after each group displays in a specific way according to their own group, they make reflections on self-experience and organize discussion, both evaluating their performance and reviewing the knowledge. There are questions and arguments, and they deepen the impression for clear explanation and further guide and explain the superficial expressions. For "positive", "negative" and "Buddha-like" students, sharing is made in different ways of discussion. Eventually, students can experience and grow up in the classroom on the basis of vivid teaching through sharing. It can be seen in "Fig. 2": Sketch of steps to implement the school-based individualized teaching action strategy under the visual threshold of new Seminar. 

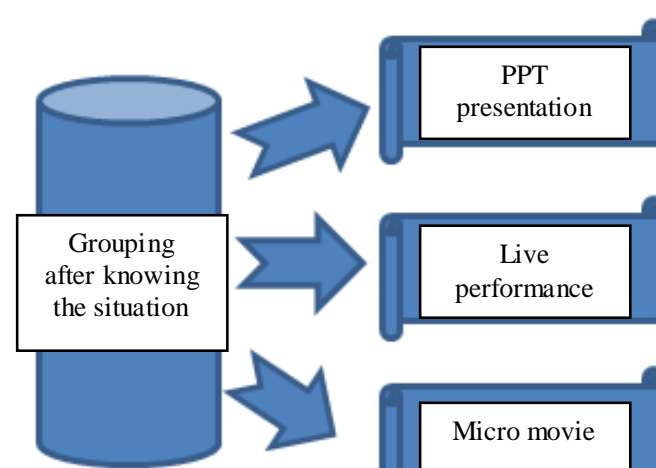

Grouping after knowing the situation
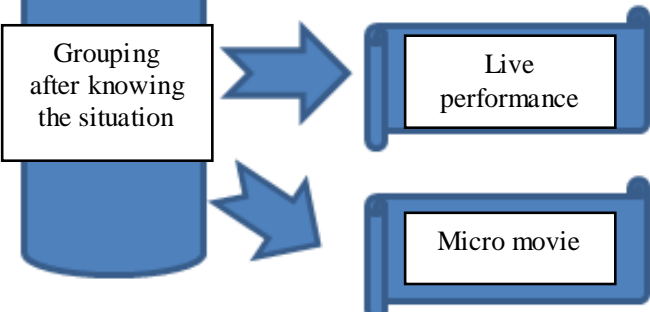

Action strategy one grouping

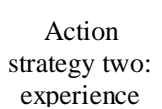

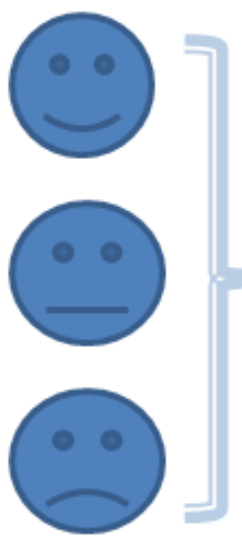

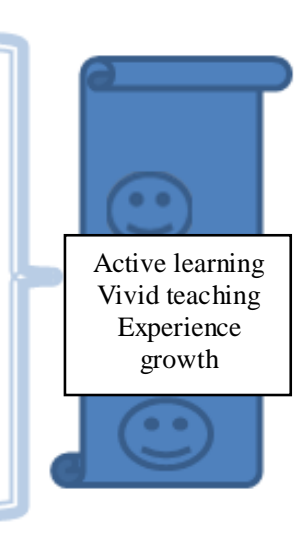

Action
strategy two:
discussion
Final goal

Fig. 2. Sketch of steps to implement the school-based individualized teaching action strategy under the visual threshold of new Seminar.

\section{B. Effect Analysis}

After the end of the course, the evaluation of students can be known through the sharing of students and the evaluation of teachers of this course in teaching evaluation system. At the same time, the effectiveness and satisfaction of learning are investigated by random questionnaires. 102 questionnaires are distributed and recovered, which conforms to the effective recovery rate. The nonstandardization of SPSS 22.0 shows that the significant probability $\mathrm{p}=0.000$, which indicates that the questionnaire has strong reliability, and the sample adequacy is high, with many common factors among variables, so the factor analysis can be carried out. ${ }^{10}$ The comprehensive survey results show that students are very satisfied with the use of such methods of teaching action, and many students express their willingness to accept new knowledge in this way; in the satisfaction of teaching resources is also prominent. One person's strength is always limited, and different ways of deductive methods of many peer groups make students understand more new things and new methods. In satisfaction of teaching effect, students believe that classroom content is no longer boring in this teaching way, and they do not want to miss any one class with a cheerful mood before each class, which shows that the students hold accepting attitude subjectively. In addition, through the "gains and experience" column in the students' training report, many students think that through this kind of teaching action, they can effectively improve their self-study ability, enhance their cooperative ability, exercise their expressive ability and optimize the learning effect. Some students believe that this teaching method is conducive to strengthening thinking and training critical thinking, which shows that this teaching action is not only conducive to the

10 Wu Minglong. Questionnaire Statistical Analysis Practice: SPSS Operation and Application [M]. Chongqing: Chongqing University Press, 2010: 206-277. improvement of teaching results, but also conducive to the training of innovative talent with all-round development. ${ }^{11}$

\section{ATTENTION AND ENLIGHTENMENT}

Although both the practice process and the effect analysis of the school-based individualized teaching action under the visual threshold of new Seminar present a peaceful situation, students like it have high satisfaction and it take into account the different types of students, there are still some details that need special attention:

\section{A. Teaching in a Single Class}

This teaching operation can't be carried out in a large class, especially a class with more than 50 students, because each semester is limited in class hours. Both grouping and discussion can't operate smoothly with too many people and teachers have difficulties in taking into account everyone, so that benign interaction and individual teaching will lose their due significance.

\section{B. To Use One's Heart with One's Emotions}

Because in the first teaching action, the teacher needs to group the students, it not only requires the teachers to have certain psychological knowledge as the basis, but also requires the teachers to observe and understand the students in daily teaching activities to determine the types of students. Many teachers of colleges and universities are not careful in teaching, so they just leave after the class. After a semester, they even don't know the names of students, which is not good for classifying the students and will affect the next teaching effect. Treating students with the heart and emotion, they can still feel.

11 Fan Wenxiang, Li Yuan, Zhang Yichun. Exploration of Seminar Teaching Model Based on the Concept Flipped classroom [J]. Higher Education of Sciences, 2017 (4): 32. 


\section{Preparing before Class}

Since it is an individualized school-based teaching action, it is very important to understand the orientation of the school before the beginning of the course to know whether the school needs the practical talent or the research talent, so that targeted guidance can be made in the course of theoretical discussion. It can be distinguished by the depth or breadth of debating problem. Only this kind of teaching action can achieve the desired goal.

\section{Reflections after Class}

Through individualized teaching action in group mode, we can not only integrate students' growth and knowledge, but also strengthen the understanding and grasp of all kinds of knowledge. This also requires the teacher to pay attention to all kinds of new things with timely and innovative mode of thinking often accompanied.

\section{CONCLUSION}

Under the visual threshold of new Seminar, the schoolbased individualized teaching action is a multi-dimensional teaching action that is based on the good combination of teaching and learning, and further develops a kind of interactive growth and individualized counseling in accordance with the school background and positioning. It can make up for the shortcomings of the traditional teaching mode, cater to the current characteristics of the times and meet the needs of the students. At the same time, it also puts forward new challenges for educators to treat every student who needs to experience and grow with heart and emotion, so that they can adapt to the ever-changing world and keep up with the pace of the times. Although the practice effect is better, in the future it still need more practice and exploration, and makes further optimization in the process.

\section{REFERENCES}

[1] Fan Wenxiang, Li Yuan, Zhang Yichun. Exploration of Seminar Teaching Model Based on the Concept Flipped classroom[J]. Higher Education of Sciences, 2017 (4): 32, 36-37. 范文翔, 李媛, 张一春. 基于翻转课堂理念的 Seminar 教学模式的探索 $[\mathrm{J}]$. 高等理科教育, 2017(4): 32, 36-37

[2] Xie Xiaoyu, Liu Shiyu. Discussion Teaching: The Practical Application of Seminar Teaching Model in Undergraduate Teaching [J]. Theory and Practice of Education, 2013 (33): 50-52. 谢晓宇, 柳 世玉.讨论式教学: Seminar 教学模式在本科教学中的实践运用 [J].教育理论与实践, 2013 (33): 50-52.

[3] Gu Riliang, Chen Fanjun, Zhang Junling et al. Important role of Seminar course in postgraduate training: Taking Seminar of plant nutrition graduate students in China Agricultural University as an example [J]. Academic Degrees \&amp; Graduate Education, 2013 (7): 42-44. 顾日良, 陈范骏, 张俊伶等. Seminar 课程在研究生培养 中的重要作用: 以中国农业大学植物营养学学科研究生 Seminar 为例 $[\mathrm{J}]$. 学位与研究生教育, 2013 (7) : 42-44.

[4] Chu Renjie. Seeking development though People-oriented and promoting Curriculum Reform by School-based [J]. Teachers, 2015 (3): 5-7. 楚任杰. 以人为本求发展 以校为本促课改 [J]. 教师, 2015 (3) : :5-7.

[5] Wang Qing. Research on the Action of Individualized Teaching in the Context of Large Classes [D]. Jiangsu: Yangzhou University, 2013: 10. 王清. 大班额背景下个别化教学的行动研究 [D].江苏: 扬州大 学, 硕士学位论文, 2013: 10.
[6] Wu Minglong. Questionnaire Statistical Analysis Practice: SPSS Operation and Application [M]. Chongqing: Chongqing University Press, 2010: 206-277. 吴明隆.问卷统计分析实务: SPSS 操作与应 用 $[\mathrm{M}]$. 重庆: 重庆大学出版社, 2010: 206-277. 